\title{
Numerical Approach for the Estimation of Throat Heat Flux in Liquid Rocket Engines
}

\author{
P. Concio $^{1}$ (1) $\cdot$ M. T. Migliorino ${ }^{1} \cdot$ F. Nasuti $^{1}$
}

Received: 1 June 2020 / Revised: 27 August 2020 / Accepted: 19 September 2020 / Published online: 7 October 2020

(c) The Author(s) 2020

\begin{abstract}
The problem of prediction of heat flux at throat of liquid rocket engines still constitutes a challenge, because of the little experimental information. Such a problem is of obvious importance in general, and becomes even more important when considering reusable engines. Unfortunately, only few indirect experimental data are available for the validation of throat heat flux prediction. On the numerical side, a detailed solution would require a huge resolution and codes able to solve at the same time combustion, boundary layer with possible finite-rate reactions, expansion up to at least sonic speed, and in some cases radiative heat flux. Therefore, it is important to validate, with the few experimental data available in the literature, simplified CFD approaches whose aim is to predict heat flux in the nozzle in affordable times. Results obtained by different numerical models based on a RANS approach show the correctness and quality of the approximations made, indicating the main phenomena to be included in modeling for the correct prediction of throat heat flux.
\end{abstract}

Keywords Liquid rocket engines $\cdot$ Heat transfer $\cdot$ CFD

\section{Introduction}

Heat flux prediction at throat of liquid rocket engines still constitutes a challenge, also because of the limited experimental information. On the other hand, being capable of predicting numerically the heat flux at the throat of a rocket thrust chamber is of paramount importance. In fact, throat region is the most critical one in terms of heat loading and requires a suitable cooling system design, which is a tradeoff between overall engine efficiency and safe structural life. This is even more important if one considers reusable engines. Many experimental studies have been focused on the measure of wall temperature and heat flux in the combustion region, that is the thrust chamber part from the injector faceplate up to the beginning of the converging section. Less experimental data are available concerning throat heat flux.

Based on paper presented at the XXV Congresso Nazionale AIDAA, Settembre 2019, Roma, Italia. (C) AIDAA, Associazione Italiana di Aeronautica e Astronautica.

P. Concio

pierluigi.concio@uniroma1.it

1 Dipartimento di Ingegneria Meccanica ed Aerospaziale, "La Sapienza"-Università di Roma, Rome, Italy
In fact, it can be easily imagined that inserting thermocouples in an experimental apparatus in the vicinity of the converging-diverging nozzle throat is much more challenging.

The numerical estimation of heat load in both combustion chamber and nozzle presents its uncertainties. Since the boundary-layer based empirical relations, as the famous Bartz equation [1], significant progresses have been made thanks to CFD developments. However, a detailed solution requires a huge resolution and codes able to solve at the same time combustion, boundary layer with possible finiterate reactions, expansion up to at least sonic speed, and in some cases radiative heat flux [2]. Therefore, it is important to validate CFD solvers for the specific objective and especially to understand the uncertainties introduced by each approximation made to get reasonable predictions in affordable times.

In this framework, a wealth of experimental information has been recently obtained and made available to scientific community by a campaign of tests conceived and carried out at Technical University of Munich (TUM) [3-6]. Unfortunately, most of information is relevant to the combustion chamber. However, results of a new test including the measure of coolant temperature increase in throat region have been made recently available $[5,6]$. These data have been considered a testbench for code validation by different 


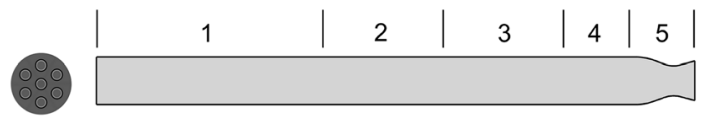

Fig. 1 Geometry of seven-injector thrust chamber. Chamber segments are indicated and numbered. Flow is from left to right

research groups making use of both commercial and inhouse CFD software [7-15].

In this paper, some aspects of modeling are deepened to get more insight on the driving phenomena for the correct prediction of throat heat flux. Focus is specifically on oxygen/methane liquid rocket engines. A simplified approach neglecting injection and combustion processes was adopted in order to evaluate its limits and capabilities. In particular, the main focus is the quantification of the effects on the throat heat flux. Analysis is carried out by a RANS solver including finite-rate chemistry and laminar turbulencechemistry interaction model.

\section{Test Case}

The oxygen/methane seven-injector thrust chamber developed and tested in Refs. $[6,16]$ is made of four water-cooled segments of circular cross-section and a fifth segment, the nozzle, also of circular cross-section and water-cooled (see Fig. 1). The cylindrical combustion chamber includes one long and three short segments. Together with the nozzle segment the total length of thrust chamber is $383 \mathrm{~mm}$. The combustion chamber inner diameter is $30 \mathrm{~mm}$ and the throat diameter is $19 \mathrm{~mm}$, resulting in a contraction ratio of 2.5 . The distance between the injectors as well as the injectorwall-distance are equal to half of the injector diameter. The operating point chosen for this test case features a mean combustion chamber pressure of 18.3 bar and a mixture ratio of 2.65 . With a total mass flow rate of $0.291 \mathrm{~kg} / \mathrm{s}$, this chamber features a combustion efficiency of $94.5 \%$.

The thrust chamber is cooled by the aforementioned two water channels. A single water channel, in fact, would not have been appropriate because of the high water temperature at the outlet of the fourth segment. For the determination of the thermal loads a calorimetric method is applied. Heating rate to each chamber segment is determined by the difference of the coolant total enthalpy between inlet and outlet.

Due to the nature of the hardware, it is difficult to measure the wall temperature in the nozzle by means of thermocouples, hence no information is available in the nozzle. Nevertheless, the wall temperature profile in the chamber is shown in Fig. 2. In this case thanks to the joint measure of wall temperature from thermocouples and of the heat flux for each segment from the measure of water temperature

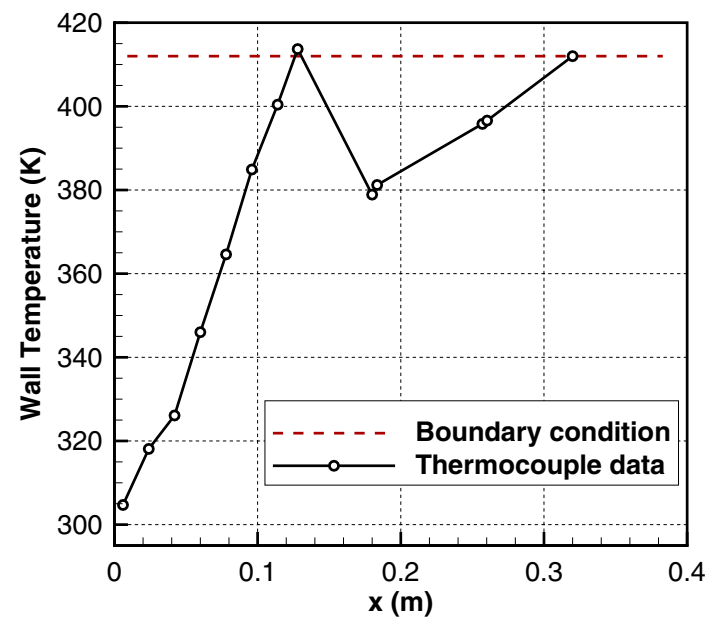

Fig. 2 Experimental wall temperature profile [16] and simulation boundary condition

increase, information about wall temperature and heat flux are made available in the combustion chamber and a single measure of heat flux is also provided for the throat segment, which is the most relevant information for the present study.

\section{Theoretical and Numerical Model}

The study of wall heat transfer at the throat of LRE thrust chambers is carried out including in principle both convection and thermal radiation models. The convective contribution is evaluated by suitable CFD modeling. The radiative contribution is evaluated by a thermal radiation model which takes information on the local flow conditions by CFD modeling. The approach has been recently presented and discussed in Refs. [2, 14, 15, 17].

The CFD solution is computed by solving the timedependent compressible Reynolds-averaged Navier-Stokes (RANS) equations for reacting mixtures of thermally perfect gases with turbulence closure according to the Spalart-Allmaras one-equation model [19]. Steady-state solutions are obtained by integrating in time the governing equation until flow variables do not change anymore (within a given tolerance). Constant values are assumed for turbulent Schmidt and Prandtl numbers, equal to $\mathrm{Sc}_{T}=0.7$ and $\operatorname{Pr}_{T}=0.9$, respectively. Oxygen/methane kinetics is modeled by means of the JL-R finite-rate chemical reaction mechanism [18, 20], shown in Table 1. As explained in Sect. 4, in this study injection and combustion processes are not modeled in the chamber. For this reason the first two reactions in Table 1 are discarded, resulting in a mechanism including 8 species and 5 reactions.

The RANS equations are numerically integrated up to the wall by an in-house CFD solver that has been validated 
Table 1 Reaction mechanism for $\mathrm{O}_{2} / \mathrm{CH}_{4}$ [18] (units: cal, $\mathrm{mol}, \mathrm{cm}, \mathrm{s}$ )

\begin{tabular}{lllll}
\hline $\mathrm{j}$ & Reaction & $A_{j}$ & $n_{j}$ & $E_{a, j}, \mathrm{cal} / \mathrm{mol}$ \\
\hline 1 & $\frac{1}{2} \mathrm{CH}_{4}+\frac{5}{4} \mathrm{O}_{2} \longrightarrow \mathrm{CO}+2 \mathrm{H}_{2}+\mathrm{O}_{2}$ & $7.82 \cdot 10^{13}$ & 0.00 & 30,000 \\
2 & $\mathrm{CH}_{4}+\mathrm{H}_{2} \mathrm{O} \longrightarrow \mathrm{CO}+3 \mathrm{H}_{2}$ & $3.00 \cdot 10^{11}$ & 0.00 & 30,000 \\
3 & $\mathrm{CO}+\mathrm{H}_{2} \mathrm{O} \rightleftharpoons \mathrm{CO}_{2}+\mathrm{H}_{2}$ & $2.75 \cdot 10^{12}$ & 0.00 & 20,000 \\
4 & $\frac{1}{4} \mathrm{H}_{2}+\frac{3}{2} \mathrm{O}_{2} \rightleftharpoons 2 \mathrm{H}_{2} \mathrm{O}+\frac{1}{2} \mathrm{O}_{2}-\frac{7}{4} \mathrm{H}_{2}$ & $1.21 \cdot 10^{18}$ & -1.00 & 40,000 \\
5 & $\mathrm{O}_{2} \rightleftharpoons 2 \mathrm{O}$ & $1.5 \cdot 10^{9}$ & 0.00 & 113,000 \\
6 & $\mathrm{H}_{2} \mathrm{O} \rightleftharpoons \mathrm{H}+\mathrm{OH}$ & $2.3 \cdot 10^{22}$ & -3.00 & 120,000 \\
7 & $\mathrm{OH}+\mathrm{H}_{2} \rightleftharpoons \mathrm{H}+\mathrm{H}_{2} \mathrm{O}$ & $2.10 \cdot 10^{8}$ & 1.51 & 3430 \\
\hline
\end{tabular}

in different operating conditions [17, 18, 21-24]. The solver adopts a finite volume Godunov-type formulation. To allow the second-order accuracy in space, a linear cell reconstruction of flow variables is carried out by using the value in the considered cell and those in the contiguous ones. A Roe approximate Riemann solver [25] for multi-block structured meshes is used. This allows to evaluate variables at cell interfaces and associated fluxes to compute the evolution in time.

\section{Results}

All simulations presented in the following have been obtained by the RANS code introduced in Sect. 3 solving the boundary layer up to wall. The computational grid is therefore designed to guarantee a value of $y^{+}$of order one at all wall boundaries. Isothermal wall boundary condition of $412 \mathrm{~K}$ is considered by enforcing thermocouple data (see Fig. 2). The resulting heat flux is then compared with experimental data to discuss the quality of prediction. Outlet boundary condition does not require specific information as supersonic flow is assumed at the nozzle exit. Numerical simulations relies on a simplified full inlet modeling, in which uniform injection of combustion products occurs through the whole injection plate area. The chemical composition of combustion products is the equilibrium composition obtained with the given mixture ratio and pressure as computed by CEA. Total pressure, temperature and chemical composition are therefore prescribed at the injector faceplate. The computational grid includes $160 \times 60$ cells (see Fig. 3).

The computed flowfield obtained by enforcing experimental chamber pressure and wall temperature is shown in Fig. 4. The lack of a loss mechanism for pressure except friction, heat exchange and release within the boundary layer, yields negligible pressure decrease in the combustion chamber. It can be clearly seen the effect of recombination reactions which increase $\mathrm{H}_{2} \mathrm{O}$ and $\mathrm{CO}_{2}$ mass fractions even at the most external part of the boundary layer. The importance of taking into account recombination reactions in the wall heat

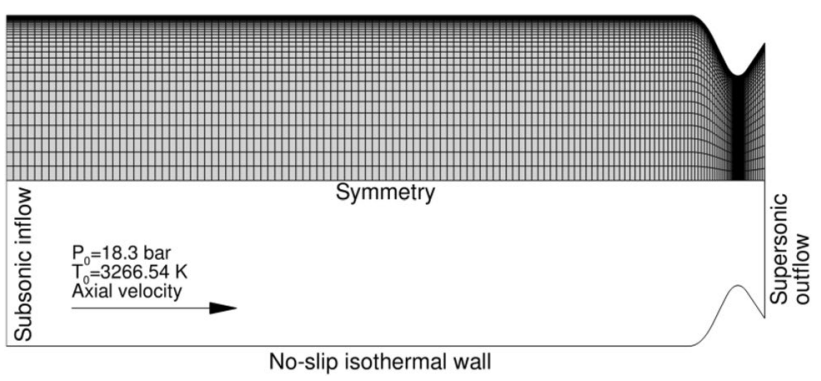

Fig. 3 Computational grid (not to scale) with boundary conditions

flux evaluations is well-known and has been discussed in Ref. [18]. The differences on heat flux values obtained with and without considering recombination reactions is shown in Fig. 5. An underestimation of about $12 \%$ on local numerical heat flux all along the thrust chamber would have been obtained considering frozen chemistry. Moreover, assuming shifting equilibrium, which is reasonable for engines using hydrogen as the fuel, yields in this case a discrepancy similar to that given by the frozen chemistry assumption. The assumption of shifting equilibrium yields, in fact, a $16 \%$ overestimation on numerical heat flux as shown in Fig. 5.

The wall heat flux obtained along the chamber with finiterate chemistry reactions is compared to experimental wall heat flux data available for each segment in Fig. 6. Because of the injection procedure, the values decrease from inlet to the converging section of the nozzle where it starts increasing up to the throat peak, and finally decreases again in the divergent section of the nozzle. A qualitative comparison of data in Fig. 6 shows a reasonable agreement for throat heat flux.

For a quantitative comparison of the computed wall heat flux it is necessary to make averages of numerical values for each segment. The results obtained by averaging wall heat fluxes in each segment is reported in Fig. 7. The comparison with experimental data shows that if one discards the region corresponding to the first two segments, the numerical simulation provides reasonable results. In fact, it is expected that the lack of any injection and combustion model does not allow any kind of agreement in the vicinity of the faceplate. 


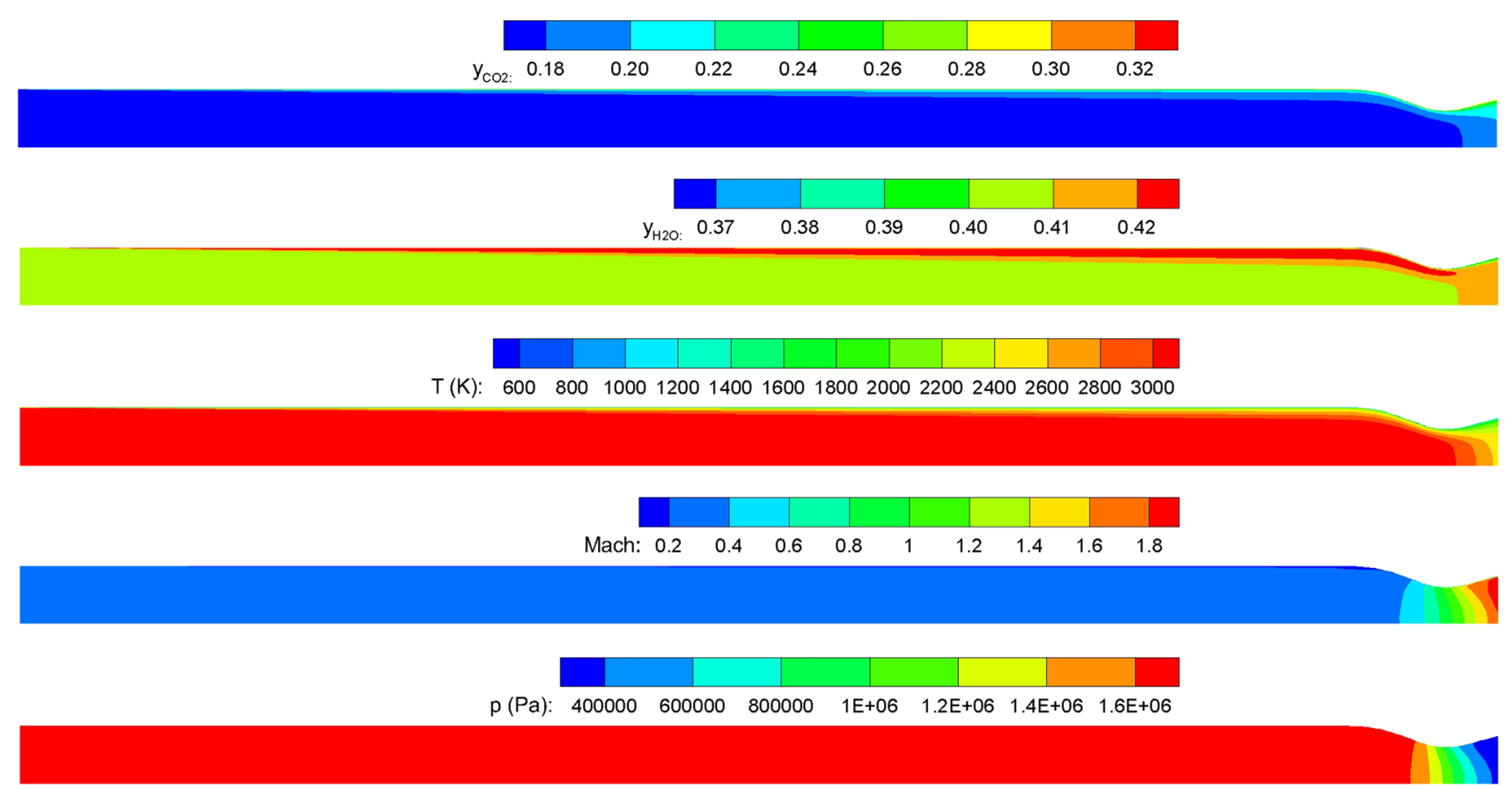

Fig. 4 Simulation results. Contour lines from top to bottom are: $\mathrm{CO}_{2}$ mass fraction, $\mathrm{H}_{2} \mathrm{O}$ mass fraction, temperature, Mach number, and pressure

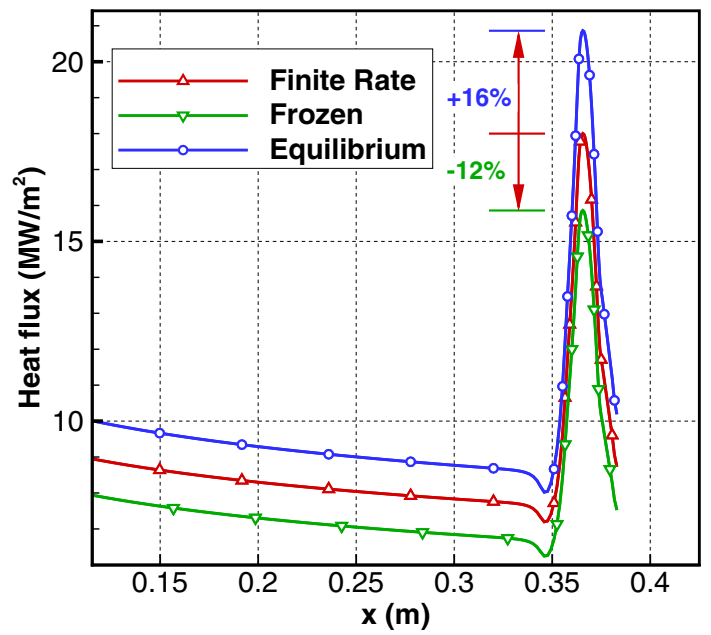

Fig. 5 Comparison of wall heat flux obtained with finite-rate, frozen and equilibrium chemistry

On the other hand, the experimental results show a decreasing trend in the combustion chamber starting from the third segment. A possible interpretation for this decreasing trend is that the chamber region where the injection and combustion processes are dominant ends at the third segment. For this reason, the present results, which neglect injection and combustion process, are compared to experimental and other numerical simulation starting from the third segment. An interesting aspect of comparison of Fig. 7 is that an increase between fourth and fifth segment in experimental data with

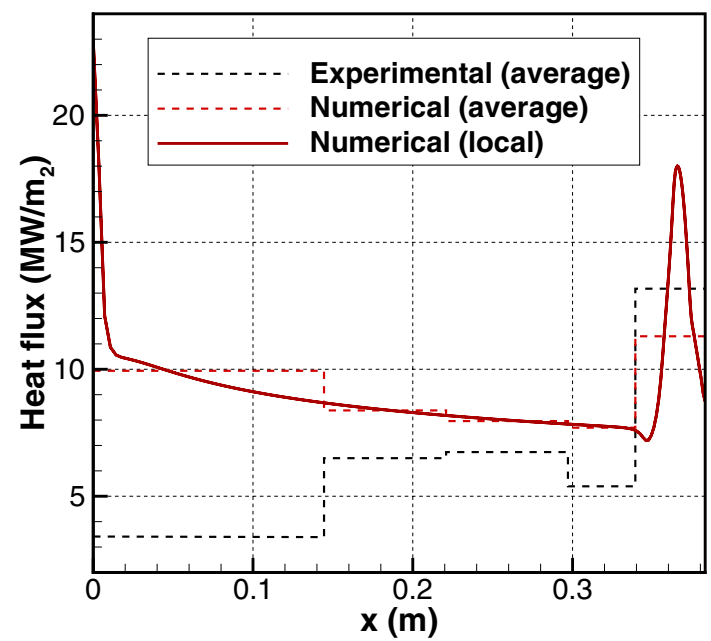

Fig. 6 Comparison of present results (Sapienza) and experimental data [11] (EXP)

respect to the numerical solution occurs. This significantly different behavior would make numerical results rather questionable. However, this aspect has been already noticed in previous studies which have found an explanation in axial heat transfer between segments $[8,12]$. In particular, due to the two water paths, one for cooling the first four segments in series and one in parallel for the cooling of nozzle segment, the nozzle segment appears to be colder than the fourth one. As a consequence the coolant of the nozzle segment is heated from the fourth chamber segment resulting 


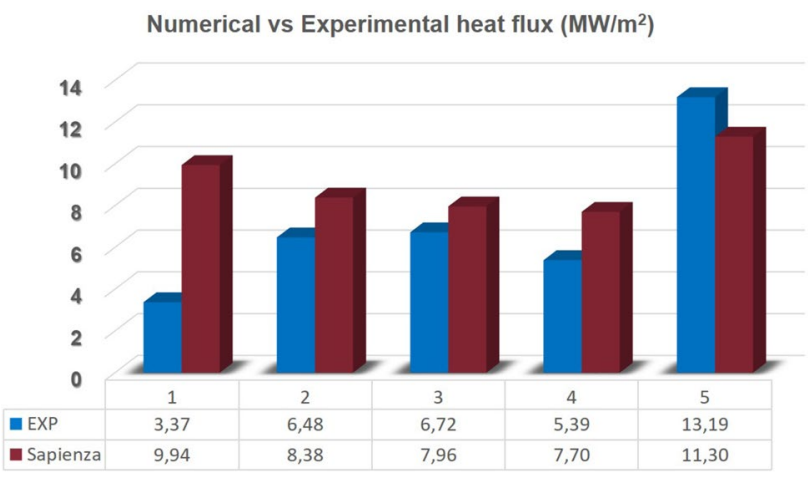

Fig. 7 Computed (Sapienza) and experimental [11] heat flux at each segment

Numerical vs Experimental heat flux $\left(\mathrm{MW} / \mathrm{m}^{2}\right)$

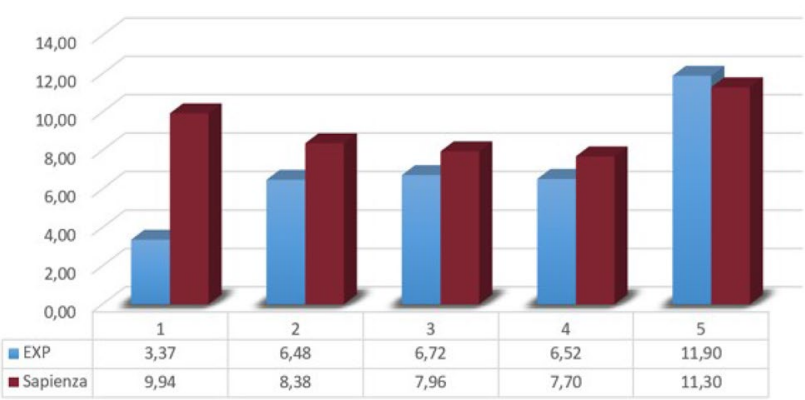

Fig. 8 Computed (Sapienza) and corrected experimental [11] heat flux at each segment

in an increase of the water temperature at the exit of the nozzle segment. If one considers the increase of temperature only due to heat coming from underlying hot gases, he makes therefore an error of overestimation of heat flux. The same is true, in the opposite direction for the fourth segment. As a consequence, one further comparison can be made by supposing that thermal power decreases between the third and the fourth segment in line with numerical expectations, quantifiable in $-3.2 \%$. Hence, the new experimental value in the fourth segment becomes $6.52 \mathrm{MW} / \mathrm{m}^{2}$ rather than the measured 5.39 MW/ $\mathrm{m}^{2}$. The correction to be considered results to be about $4.39 \mathrm{~kW}$, supplied by the fifth segment, which, due to energy balance, reduces its heat content by the same amount. The corrected experimental value in the fifth segment results to be $11.9 \mathrm{MW} / \mathrm{m}^{2}$. Corrected experimental data are compared with numerical results in Fig. 8.

\section{Conclusion}

Focusing on the capability of predicting the wall heat flux at throat, the present analysis has shown that considering a simplified injection and combustion model can provide results close to experimental data. A simplified approach considers injection of combustion products at equilibrium conditions for the given chamber pressure and oxidizer to fuel mixture ratio. Despite the lack of modeling of the injection and combustion regions and the consequent discrepancies with respect to experimental data of heat flux, the predicted value at throat is closer to the experimental data than in other simulations available in literature and mostly focused on combustion chamber analysis. Moreover, the discrepancy with experimental data is significantly reduced if the heat exchange between the separate cooling systems of chamber and throat is taken into account.

Funding Open access funding provided by Università degli Studi di Roma La Sapienza within the CRUI-CARE Agreement.

\section{Compliance with ethical standards}

Conflict of interest On behalf of all authors, the corresponding author states that there is no conflict of interest.

Open Access This article is licensed under a Creative Commons Attribution 4.0 International License, which permits use, sharing, adaptation, distribution and reproduction in any medium or format, as long as you give appropriate credit to the original author(s) and the source, provide a link to the Creative Commons licence, and indicate if changes were made. The images or other third party material in this article are included in the article's Creative Commons licence, unless indicated otherwise in a credit line to the material. If material is not included in the article's Creative Commons licence and your intended use is not permitted by statutory regulation or exceeds the permitted use, you will need to obtain permission directly from the copyright holder. To view a copy of this licence, visit http://creativecommons.org/licenses/by/4.0/.

\section{References}

1. Bartz, D.R.: A simple equation for rapid estimation of rocket nozzle convective heat transfer coefficients. Jet Propuls. 27, 49-53 (1957)

2. Leccese, G., Bianchi, D., Betti, B., Lentini, D., Nasuti, F.: Numerical investigation on radiative heat loads in liquid rocket thrust chambers. J. Propuls. Power 35, 318-326 (2019)

3. Celano, M.P., Silvestri, S., Schlieben, G., Kirchberger, C., Haidn, O., Knab, O.: Injector characterization for a gaseous oxygenmethane single element combustion chamber. Progress Propuls. Phys. 8, 145-164 (2016)

4. Celano, M. P., Silvestri, S., Bauer, C., Perakis, N., Schlieben, G., Haidn, O. J.: Comparison of single and multi-injector goc/ch4 combustion chambers. In: AIAA Paper, pp. 2016-4990 (2016)

5. Silvestri, S., Celano, M. P., Schlieben, G., Haidn, O. J.: Characterization of a multi-injector gox/ch4 combustion chamber. In: AIAA Paper, pp. 2016-4992 (2016)

6. Silvestri, S., Bauer, C., Lungu, P., Haidn, O. J.: Axial and azimuthal heat load distribution in 7-injector gox/gch4 combustion chamber. In: AIAA Paper, pp. 2018-4552 (2018)

7. Chemnitz, A., Sattelmayer, T., Roth, C., Haidn, O., Daimon, Y., Keller, R., Gerlinger, P., Zips, J., Pfitzner, M.: Numerical 
investigation of reacting flow in a methane rocket combustor: turbulence modeling. J. Propuls. Power 34, 864-877 (2018)

8. Daimon, Y., Negishi, H., Silvestri, S., Haidn, O. J.: Conjugated combustion and heat transfer simulation for a 7 element gox/gch4 rocket combustor. In: AIAA Paper, pp 2018-4553 (2018)

9. Lapenna, P., Amaduzzi, R., Durigon, D., Indelicato, G., Nasuti, F., Creta, F.: Simulation of a single-element GCH4/GOx rocket combustor using non-adiabatic flamelet method. In: AIAA Paper, pp 2018-4872 (2018)

10. Muller, H., Zips, J., Pfitzner, M., Maestro, D., Cuenot, B., Menon, S., Ranjan, R., Tudisco, P., Selle, L.: Numerical investigation of flow and combustion in a single-element gch4/gox rocket combustor: a comparative les study. In: AIAA Paper, pp. 2016-4997 (2016)

11. Perakis, N., Haidn, O. J., Eiringhaus, D., Rahn, D., Zhang, S., Daimon, Y., Karl, S., Horchler, T.: Qualitative and quantitative comparison of rans simulation results for a 7-element gox/gch4 rocket combustor. In: AIAA Paper, pp. 2018-4556 (2018)

12. Perakis, N., Rahn, D., Eiringhaus, D., Haidn, O.: Heat transfer and combustion simulation of a 7-element gox/gch4 rocket combustor. In: AIAA Paper, pp. 2018-4554 (2018)

13. Roth, C. M., Haidn, O., Chemnitz, A., Sattelmayer, T., Frank, G., Müller, H., Zips, J., Keller, R., Gerlinger,P. M., Maestro, D., Benedicte, C., Riedmann, H., Selle, L.: Numerical investigation of flow and combustion in a single-element gch4/gox rocket combustor. In: AIAA Paper, pp. 2016-4995 (2016)

14. Nasuti, F., Frezzotti, M. L., Concio, P.: Numerical estimation of peak heat flux at throat of liquid rocket engines. In: Proceedings of 32nd International Symposium on Space Technology and Science (ISTS), Fukui, Japan, June 15-21, 2019 (2019)

15. Nasuti, F., Concio, P., Indelicato, G., Lapenna, P. E., Creta, F.: Role of combustion modeling in the prediction of heat transfer in LRE thrust chambers. In: 8th European Conference for Aeronautics and Aerospace Space Sciences (EUCASS). Paper 503 (2019)
16. Silvestri, S., Celano, M. P., Roth, C., Haidn, O. J.: Transregio SFBTR40 test case bks-2. Technical report, Technische Universität München, Lehrstuhl für Flugantriebe (2017)

17. Leccese, G., Bianchi, D., Betti, B., Lentini, D., Nasuti, F.: Convective and radiative wall heat transfer in liquid rocket thrust chambers. J. Propuls. Power 34, 318-326 (2018)

18. Betti, B., Bianchi, D., Nasuti, F., Martelli, E.: Chemical reaction effects on heat loads of $\mathrm{CH}_{4} / \mathrm{O}_{2}$ and $\mathrm{H}_{2} / \mathrm{O}_{2}$ rockets. AIAA J. 54, 1693-1703 (2016)

19. Spalart, P.R., Allmaras, S.R.: A one-equation turbulence model for aerodynamic flow. La Recherche Aèrospatiale 1, 5-21 (1994)

20. Jones, W.P., Lindstedt, R.P.: Global reaction schemes for hydrocarbon combustion. Combust. Flame 73, 233-249 (1988)

21. Pizzarelli, M., Nasuti, F., Paciorri, R., Onofri, M.: Numerical analysis of three-dimensional flow of supercritical fluid in cooling channels. AIAA J. 47, 2534-2543 (2009)

22. Betti, B., Pizzarelli, M., Nasuti, F.: Coupled heat transfer analysis in regeneratively cooled thrust chambers. J. Propuls. Power 30, 360-367 (2014)

23. Bianchi, D., Betti, B., Nasuti, F., Carmicino, C.: Simulation of gaseous oxygen/hydroxyl-terminated polybutadiene hybrid rocket flowfields and comparison with experiments. J. Propuls. Power 31, 919-929 (2015)

24. Bianchi, D., Nasuti, F., Carmicino, C.: Hybrid rockets with axial injector: Port diameter effect on fuel regression rate. J. Propuls. Power 32, 984-996 (2016)

25. Roe, P.L.: Approximate Riemann solvers, parameter vectors and difference schemes. J. Comput. Phys. 43, 357-372 (1981)

Publisher's Note Springer Nature remains neutral with regard to jurisdictional claims in published maps and institutional affiliations. 